Journal of Humanities and Social Sciences Studies (JHSSS)

ISSN: 2663-7197

DOI: 10.32996/jhsss

Journal homepage: https://al-kindipublisher.com/index.php/jhsss

\title{
Vulnerability of the Poor and Non-poor Households: A Case Study of Neboda West Grama Niladhari Division of Dodangoda Divisional Secretariat in Sri Lanka
}

Dr. M. A. Shantha Wijesinghe

Department of Geography, University of Sri Jayewardenepura, Sri Lanka.

Corresponding Author: Dr. M. A. Shantha Wijesinghe, E-mail: shanthawi@sjp.ac.lk

\section{ARTICLE INFORMATION}

Received: October 21, 2020

Accepted: November 25, 2020

Volume: 2

Issue: 6

DOI: 10.32996/jhsss.2020.2.6.24

KEYWORDS

Access to credit market, Income variation and diversification, Networks, Poor and Non-poor, Physical assets, Safety nets, Vulnerability

\section{ABSTRACT}

Poverty is a complex and multifaceted phenomenon with many forms and causes. It is normally measured quantitatively by using income criterion. But understanding poverty only in terms of income criterion can misrepresent its nature and underlying causes. It is a much broader and deeper issue of deprivation mainly associated with both quantitative and qualitative aspects. It is essential to place considerable values on both quantitative and qualitative aspects in understanding poverty. Thus, vulnerability is one of the criteria which is used to understand poverty in these two aspects. Vulnerability is a constant companion of material and human deprivation, given the circumstances of the poor and the near-poor or non-poor. It means the probability of being exposed to a number of risks. It is generally accepted that poor people are more vulnerable in various circumstances than non-poor people due to many reasons. Thus, this paper attempts to analyse the nature of vulnerability of the poor and non-poor households and the root causes leading to their level of vulnerability. For this purpose, Neboda West Grama Niladhari Divison of Dodangoda Divisional Secretariat in Sri Lanka was selected for the study. A sample of fifty households was selected for the study by following stratified random sampling technique. Questionnaire and the in-depth interviews were used for data gathering. In order to examine whether there is a significant difference between poor and non-poor households regarding quantitative aspects of vulnerability, mean, standard deviation, coefficient of variation and the Analysis of Variance (ANOVA) were used. For analysing qualitative aspects of vulnerability relating to these two groups absolute and percentage values were used. As the findings, this study disclosed that there is a significant difference between poor and non-poor households regarding vulnerability. As its quantitative aspects income and its variability and as the qualitative aspects ownership to physical assets, education, income diversification, links to networks, safety nets and access to credit market significantly vary between these two groups by confirming significant difference of the ability to face adverse shocks.

\section{Introduction}

Poverty is a complex and multifaceted phenomenon with many forms and causes. It is generally measured and identified quantitatively, particularly on the income criterion. But understanding poverty only in terms of adequate income, can misrepresent its nature and its underlying causes. It is a much broader and deeper issue of deprivation than having an income below a poverty line. It is essential to place considerable values on qualitative aspects in understanding poverty. As described by Chambers (1989), there are many more aspects of deprivation other than income poverty including vulnerability, powerlessness, isolation and humiliation. Thus, the concept of vulnerability is one of the criteria that is used to understand poverty quantitatively and qualitatively.

K C AL-KINDI CENTER $\mathbf{R}$
D Your gateway to world-class research
Published by Al-Kindi Center for Research and Development. Copyright (c) the author(s). This is an open access article under CC BY license (https://creativecommons.org/licenses/by/4.0/) 
Vulnerability is a constant companion of material and human deprivation, given the circumstances of the poor and the nearpoor. It means the probability of being exposed to a number of risks. The risks that poor people face as a result of their circumstances, are the causes of their vulnerability. But the deeper cause is the inability to reduce or mitigate risk or cope with shocks. Normally, low levels of physical, natural and financial assets make poor people vulnerable to negative shocks. Lack of adequate assets can set up a vicious downward spiral in which actions to cope in the short term, worsen deprivation in the long term. Thus, vulnerability is an aspect closely related with poverty, as it is the risk that poor people face as a result of different circumstances.

It is generally accepted that poor people are more vulnerable in various circumstances than non-poor people. Particularly non-poor have fixed source of income and sometime they derive their monthly income from different sources. They have the capability to face adverse shocks in different circumstances and their physical assets, family relations, social security, savings and credit culture protect them against vulnerability. Consequently, they have been able to minimize the probability of being exposed to number of risks. But the situation of the poor is completely different. They normally do casual work and their low levels of physical assets, lack of family and social support, poor access to credit market and savings, poor links with social networks have caused their inability to reduce or mitigate risks. Under this background, it is timely to know how these two groups face to the adverse shocks and the causes affecting to reduce or mitigate their risks in various circumstances. Thus, this paper attempts to analyze the nature of vulnerability of the poor and non-poor households in Neboda West Grama Niladhari Divison of Dodangoda Divisional Secretariat in Sri Lanka. Such a study provides useful guidelines to minimize poverty on quantitative terms as well as on qualitative terms.

\section{Literature Review}

This research paper is mainly based on the concept of vulnerability addressed in World Development Report (2000/2001), as it comprehensively explains its nature and the dimensions. There are many theoretical and empirical studies on vulnerability done in different countries but it is evident that such studies have not conceptualized the concept to the level of the World Development Report (2000/2001).

Chambers (1989) has particularly addressed the concept of vulnerability in emphasizing poverty in qualitative dimensions and how the poor cope with by following various strategies. The coping strategies followed by the poor when they are vulnerable have been addressed in this paper. Ligon and Schechter (2003) have discussed in their paper of how to measure vulnerability based on income and other criteria. In this study, they have particularly emphasized the qualitative dimensions of vulnerability. Katsushi, Wang \& Kang (2009) have studied the effect of taxation on poverty and vulnerability in rural China. How the tax effects to increase the level of poverty and then how poor becomes more vulnerable have been discussed in this paper. Gaiha, Imai and Kang (2007) have discussed the dynamics of poverty and how such dynamics are related to vulnerability of the poor in Vietnam. Changing levels of poverty and how such dynamics make poor more vulnerable have been addressed in this paper. Lant, Asep and Sudamo (2000) have proposed a quantitative method of measuring vulnerability particularly based on income criterion. It is a methodological paper, suggesting techniques to measure vulnerability in quantitative terms. Jonathan (1995) has discussed how income and consumption is smoothened by the poor. The strategies followed by the poor in smoothening income and consumption in a vulnerable situation, have been discussed in that paper. Dercon (2002) has discussed how to minimize the risk of income by following various coping strategies and the importance of safety nets in minimizing the risk. Different safety nets such as social links and networks have particularly been emphasized in this regard. Elbers and Gunning (2003) have introduced a Stochastic Dynamic Model for understanding and measuring vulnerability. That is a methodological paper suggesting a model to measure vulnerability, particularly based on income. Raghbendra (2009) has addressed poverty, under-nutrition and vulnerability in rural India and emphasized the importance of public works verses food subsidy programmes in reducing vulnerability. This paper has rejected providing subsidies in a vulnerable situation and instead proposed the significance of public work programme as a productive instrument. Suryahadi and Sumarto (2003) have also done a study on poverty and vulnerability in Indonesia by assessing the economic crisis of the country, as the poverty rate significantly increased after the economic crisis. This study has discussed how the economic crises of the country badly affect to increase poverty levels making the poor more vulnerable.

Among researchers who have directly addressed the subject of vulnerability referring to Sri Lanka, Silva (2003) has discussed the perceptions of vulnerability and coping in conflict-affected populations in the Dry Zone of Sri Lanka. How the conflictaffected people in dry zone face when they are vulnerable and how they follow different coping strategies have been discussed in this paper. Attanayake (2003) has also done a study on poverty and health by relating vulnerability in plantation community in Sri Lanka. How the health of plantation community makes them vulnerable and its relevant causes have been addressed in the paper. CARE International (2000) has assessed household livelihood security in LTTE controlled areas in 
Wanni District. From this study, the uncertainty of livelihoods and its impact have been discussed in assessing the livelihood strategies of the people in Wanni District. Yamane (2003) has also done a study on the subject of rethinking vulnerability to climate change in Sri Lanka. How the climate makes people vulnerable and how they react in such situation have been addressed here. UN-Habitat (2013) has assessed climate change vulnerability in Negombo, Sri Lanka. This is also similar to Yamane's (2003) study by addressing the impact of climate change on vulnerability. Fauci, Bonciani and Guerra (2012) have analysed the impact of Tsunami on the quality of population in Sri Lanka, focussing on the factors that have contributed to an increase in the people's susceptibility to the impacts of hazards relating to their vulnerability. In this study, how Tsunami and people's susceptibility of such hazards affect to make people more vulnerable has been addressed.

It is clear that many studies have been done relating to poverty and vulnerability but there is a basic lacuna of knowledge and literature which combine all dimensions of vulnerability, as addressed by the World Bank Report (2000/2001). Even though many studies can be cited, such studies only cover one or few aspects of vulnerability and those have not conceptualized vulnerability to the level, as addressed in the World Development Report. As World Development Report (2000/2001) provides a comprehensive framework for understanding vulnerability, particularly of poor, this study attempts to fulfil the gap of such empirical knowledge in poverty alleviation strategies in Sri Lanka.

\section{Methodology}

Methodology adopted for the study is as follows.

\subsection{Selection of Grama Niladhari (GN) Division to the study}

Neboda West GN Division of Dodangoda Divisional Secretariat is the division selected for this study. Selection of this GN division was based on secondary data and the discussions held with village level officers. As the secondary data, percentage of the families below income-based poverty line and the poverty levels of GN Divisions, as measured by Unsatisfied Basic Needs Index (UBNI), were comparatively used in identifying this poorer GN division for the study. Income based poverty line is the main criteria used by the government of Sri Lanka to identify the poverty of households. In addition, UBNI is also used and it is calculated by using the criteria such as sanitary facilities, use of kerosene for lightening and firewood for cooking, condition of the wall, floor and roof of the house, educational level of the head and members of the household and the number of paid employees of the household. Thus, the selected Neboda West GN division is reporting the highest percentage of the families below income-based poverty line (43.2\%) and it is also poorer GN division in terms of UBNI reporting a lower rank of 2 out of $1-5$ scale (Divisional Secretariat, 2017). The accuracy of the selected GN divisions was further confirmed by the discussions held with village level officers in the Divisional Secretariat.

Total number of households of this village is 148 which is considered as the total population of this study. Out of them 64 households belong to poor category and the rest is non-poor households according to income-based poverty line and UBNI. One-third of total population, which is roughly equal to 50 households, was selected as the sample for the study. Proportionately distributed stratified random sampling technique was used in selecting households from both categories as mentioned in Table 1.

Table 1: Distribution of the sample by poor and non-poor households

Source: Divisional Secretariat, 2018

\begin{tabular}{|l|l|l|l|c|}
\hline Selected village & $\begin{array}{l}\text { Total number of } \\
\text { households in the village }\end{array}$ & $\begin{array}{l}\text { No. of poor and non-poor } \\
\text { households }\end{array}$ & $\begin{array}{l}\text { Proportionate distribution of } \\
\text { the sample of 50 households }\end{array}$ \\
\hline 807 C Neboda West & & Poor & 64 & 22 \\
\cline { 3 - 5 } & \multirow{2}{*}{148} & Non- & 84 & 28 \\
\hline
\end{tabular}

The selection of 22 poor households from 64 and 28 non-poor households from 84 was done by using GOOGLE Random Number Generator. 


\subsection{Conceptual framework of the paper}

Since the vulnerability is a dynamic concept, its measurement centers on the variability of income or consumption or on the variability of other dimensions of well-being. Thus, it was identified on quantitative and qualitative terms in the research. On quantitative terms, the variability was measured by the standard deviation or coefficient of the variation of income but such coefficient of income is, moreover, a measure after the fact (World Development Report, 2000/2001). Therefore, the needed also focused on qualitative indicators that make it possible to assess a household's risk beforehand. Thus, the following information both on the household and on its links to informal networks and formal safety nets were examined.

A household's physical assets: Those assets that can be sold to compensate for temporary loss of income are a measure of its capacity to self-insure. In this regard, the liquidity of assets is important than the total value of the assets.

Human capital: It was assumed that households with limited education tend to be more subject to income fluctuations and less able to manage risk.

Income diversification: The extent to which income sources are diversified is also used as a qualitative indicator to assess vulnerability. But this may be a misleading indicator of risk exposure because a single low-risk activity could be more preferable than multiple high-risk activities that are strongly covariant. So, more diversification is not necessarily less risky (World Development Report, 2000/2001).

Links to networks: Family-based networks, occupation-based groups of mutual help, rotating savings and credit groups or associations to which a household belongs - all parts of the household's social capital - was also considered as a source of transfers in cash or some other way in the event of a calamity.

Participation in the formal safety nets: It was also assumed that household's vulnerability is reduced if it is entitled to social assistance, unemployment insurance, pensions and other publicly provided transfers.

Access to credit market: Similarly, it was assumed that a household's vulnerability is reduced if it has access to credit for consumption smoothening.

According to above explanation, conceptual framework of the research paper is outlined as indicated in Figure 1.

\section{Quantitative concepts}

Income and its variability

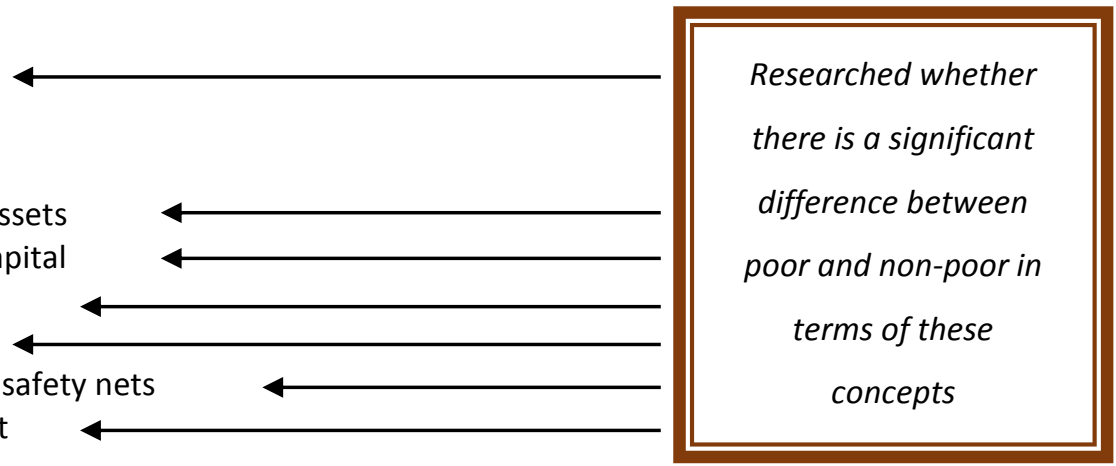

Figure 1: Conceptual frame of the study based on World Development Report, 2000/2001

\subsection{Hypothesis tested}

As per the conceptual model depicted in Figure 1, the following null and alternative hypotheses were tested in the research process.

\section{Hypothesis 1}

Null Hypothesis $-\mathrm{H}_{0}$ - There is no significant difference of mean and the variation of income between poor and non-poor households

Alternative Hypothesis - $\mathrm{H}_{1}$ - There is a difference of mean and the variation of income between poor and non-poor households.

This hypothesis 1 was tested at 0.05 significant level. 


\section{Hypothesis 2}

Null Hypothesis - $\mathrm{H}_{0}$ - Three is no significant difference of the vulnerability: ability to face adverse shocks by poor and nonpoor households.

Alternative hypothesis - $\mathrm{H}_{1}$ - There is a difference of the ability to face adverse shocks by poor and non-poor households.

Hypothesis 2 was tested by qualitative data and information.

\subsection{Methods of data collection and analysis}

Data were gathered from primary and secondary sources so that the objectives could be achieved. As the secondary sources, books and articles, poverty reports and resource profile of Dodangoda Divisional Secretariat were used. Poverty reports were used to identify poorer GN division and to demarcate poor and not-poor households of the selected GN division. Books and articles were used to review literature about the concept. Particularly, World Development Report, 2000/2001 was used to conceptualize the study.

As the primary data sources, discussions with the officers of Dodangoda Divisional Secretariat and the questionnaire were used. Discussions were held to identify poorer GN division and the questionnaire was used to examine the nature and the causes of vulnerability of poor and non-poor households.

As indicated in the conceptual framework of Figure 1, this study consists of two major parts. First part is the quantitative aspect of vulnerability which was measured by the mean, standard deviation and the coefficient of variation of income. For the analysis of this part mean, standard deviation, coefficient of variation and the Analysis of Variance (ANOVA) were used. Particularly by applying ANOVA, hypothesis was tested at 0.05 significant level. Second part of the study was focussed on the analysis of the qualitative aspects of vulnerability which emphasize the ability to face adverse shocks by poor and non-poor households in terms of the criteria highlighted in conceptual frame.

\section{Results and Discussion}

\subsection{The first section: Quantitative analysis}

The first section focuses on quantitative aspect of vulnerability which is measured by the mean, standard deviation and the coefficient of variation of income. For the analysis of this section, mean, standard deviation, coefficient of variation and the Analysis of Variance (ANOVA) were used.

As the first step of the analysis, descriptive statistics such as mean, standard deviation and the coefficient of variation of income were calculated in order to understand whether there is a difference of these measures by poor and non-poor households in selected GN division. Thus, descriptive statistics relating to income and its variability are presented in Table 2 .

\begin{tabular}{|l|c|c|}
\hline & \multicolumn{2}{|c|}{ Neboda West } \\
\hline Measure & 2000 & 12000 \\
\hline Minimum income & 17500 & 33000 \\
\hline Maximum income & 15500 & 21000 \\
\hline Range & 10068.75 & 21968.57 \\
\hline Mean & 4347.22 & 5706.23 \\
\hline Standard Deviation & 0.43 & 0.26 \\
\hline Coefficient of variation & $43 \%$ & $26 \%$ \\
\hline Skewness & -0.140 & +0.167 \\
\hline
\end{tabular}

Table 2: Descriptive statistics of monthly income of the poor and non-poor households in selected GN division

Source: Based on field data, 2019 
As indicated by the Table 2, it is very clear that the average monthly income varies in the selected GN division by poor and non-poor households. While poor households report average monthly income of Rs. 10069, non-poor households record a higher value of Rs. 21969.

As the average monthly income does not give any indication of the variability of income of each group, standard deviation for each group was calculated to understand their dispersion of income from the mean. Thus, it indicates that the dispersion of income from the mean is high in non-poor category, as their standard deviation is comparatively larger than that of poor category. But it may be somewhat misleading to compare the absolute magnitude of the standard deviations, as it could be expected fairly large standard deviation with a very large mean. Therefore, it is more practical to compare these two groups with respect to their relative homogeneity, as these two groups have very different means. In such situations, coefficient of variation, which indicates the size of the standard deviation relative to that of the mean, is more practicable and useful than the standard deviation, in understanding the variability of income of these two groups. Coefficient of income variation of the poor group reports $43 \%$ compared to the value of $26 \%$ of non-poor category. Thus, it is so clear that the coefficient of variation is higher in poor group than the non-poor group by confirming the variability of monthly income of poor group is higher than that of non-poor group.

From the above analysis it was clear that the income of poor varies from that of non-poor households. But these absolute values of income do not merely enough to conclude that the income of poor significantly varies from that of non-poor, as the difference may happen by chance. Therefore, it is essential to examine this difference is statistically significant or not or whether it happened by chance due to sampling or some other error. For this significant test, Analysis of Variance (ANOVA) was run for the income data of poor and non-poor households in order to test the null hypothesis: There is no significant difference of the mean income between poor and non-poor households. Accordingly, the output of ANOVA is presented by Table 3.

\begin{tabular}{|l|l|l|l|c|}
\hline \multicolumn{1}{|c|}{ Variation } & \multicolumn{1}{|c|}{ Sum of Squares } & \multicolumn{1}{|c|}{$\begin{array}{c}\text { Degrees of freedom } \\
\text { (df) }\end{array}$} & \multicolumn{1}{|c|}{$\begin{array}{c}\text { Variance } \\
\text { estimation }\end{array}$} & F value \\
\hline Total (TSS) & 514288.64 & $\mathrm{~N}-1=50-1=49$ & & 113.27 \\
\hline Between (BSS) & 361219.03 & $\mathrm{~K}-1=2-1=1$ & 361219.03 & \\
\hline Within (WSS) & 153069.61 & $\mathrm{~N}-\mathrm{K}=50-2=48$ & 3188.95 & \\
\hline
\end{tabular}

Table 3: ANOVA output relating to the difference of mean income between poor and non-poor households.

Source: Based on Field Data, 2019

According to Table 3, it is clear that Between Sum of Squares (BSS), which indicates the amount of explained variation out of the Total Sum of Squares (TSS) is higher than the unexplained variation denoted by Within Sum of Squares (WSS). As a result, $\mathrm{F}$ value has reported as high as a value of 113.27. According to 1 and 48 degrees of freedom at 0.05 significant level, table value of $F$ distribution only reports 4.043. Thus, calculated $F$ value (113.27) exceeds the theoretical value by rejecting the nullhypothesis. Accordingly, it can be concluded that the income of poor and non-poor households significantly varies and it has not happened by chance at all. This is further confirmed, as the null-hypothesis can also be rejected even at 0.001 significant level with high confidence. Value of $F$ table even at 0.001 level for 1 to 50 degrees of freedom is only 12.22 and that value is also far below the value of 113.27. Thus, the alternative hypothesis can clearly be accepted by concluding that there is a significant difference of mean income between these groups.

\subsection{The second section: Qualitative analysis}

Vulnerability is a dynamic concept. Therefore, its measurement must be cantered on the variability of quantitative and qualitative dimensions. But as pointed out in methodology, quantitative instruments of income are some measures after the fact. Therefore, we need focusing on qualitative indicators that make it possible to assess a household's risk beforehand. Thus, this section focuses on the variability of such qualitative dimensions. In this regard, households and their links to informal networks and formal safety nets were examined in terms of the following criteria.

\subsubsection{Households' physical assets}

Household assets that can be sold to compensate for temporary loss of income, are a measure of its capacity to self-insure. In this regard, the liquidity of assets is important than the total value of the assets. However, the ownership of major assets like 
living place, paddy fields and other lands, motor vehicles, bicycle and three wheelers and jewellery was examined in order to understand whether poor and non-poor households have some kind of capacity of self-insurance. In that examination, priority was given to the liquidity of assets, as the extent to which the assets can be liquidized, is very important in minimising the risk of vulnerability.

Accordingly, Table 4 indicates the ownership of different physical assets by poor and non-poor households in the selected GN division.

\begin{tabular}{|l|c|c|}
\hline \multirow{2}{*}{ Ownership of physical asset } & \multicolumn{2}{c|}{ Neboda West GN Division } \\
\cline { 2 - 3 } & $\%$ of poor households & \multicolumn{2}{c|}{} \\
Living house (own) & 87.0 & 100.0 \\
\hline Living house on rent & 13.0 & 63.0 \\
\hline Paddy lands & 5.0 & 74.0 \\
\hline Other lands & 4.0 & 12.0 \\
\hline Any kind of motor vehicle & - & 72.0 \\
\hline Bicycle, motor bicycle and three wheelers & 12.0 & 3.0 \\
\hline Cattle, cows, chicken and goats & 5.0 & 100.0 \\
\hline Jewelleries & 71.0 & \\
\hline
\end{tabular}

Table 4: Ownership to physical assets by poor and non-poor households

Source: Field Data, 2019

Table 4 noticeably discloses that there is a clear difference of the ownership to different physical assets by poor and non-poor households. That difference is more salient regarding the ownership of paddy lands and other lands and the ownership to bicycle, motor cycle and three wheelers.

However, ownership to different physical assets is not an important point in understanding the reality of vulnerability. Instead, the extent to which these different assets can immediately be liquidized is very important in assessing the capacity of self-insurance of these two groups. In assessing the extent to which these physical assets can immediately be sold to compensate for the temporary loss of income, ownership to the assets like motor vehicles, foot and motor bicycles, three wheelers and jewelleries is very important. Particularly, ownership to jewelleries is decisive as they can easily be sold or pawned at any time without problem. Accordingly, the data in Table 4 discloses that there is a significant difference of the ownership of these assets as well between poor and non-poor households.

\subsubsection{Human capital of poor and non-poor households}

Nature and the quality of human capital of households can be measured by various criteria. Education, training, experience and the knowledge and skills of the members of the household are the criteria commonly used. However, Human Development Report (2000/2001) has pointed out that the households with limited education tend to be more subject to income fluctuations. In order to examine the validity of this matter, this study also examined whether there is a difference of the educational level of poor and non-poor households in the selected GN division. For this purpose, educational level of the head householder was taken into consideration. 
Accordingly, Table 5 indicates the educational level of the head householder of poor and non-poor households.

\begin{tabular}{|l|c|c|}
\hline \multirow{2}{*}{ Educational level of head householder } & \multicolumn{2}{c|}{ Neboda West GN Division } \\
\cline { 2 - 3 } & $\%$ of poor households & $\begin{array}{c}\text { \% of non-poor } \\
\text { households }\end{array}$ \\
\hline No schooling & 9.0 & 14.0 \\
\hline Primary & 55.0 & 79.0 \\
\hline Secondary & 36.0 & 7.0 \\
\hline Higher & - & 100.0 \\
\hline Percentage total & 100.0 & $0.26(26 \%)$ \\
\hline Coefficient of variation & & $0.43=(43 \%)$ \\
\hline
\end{tabular}

Table 5: Educational level of the head householder by poor and non-poor households

Source: Field data, 2019

Table 5 clearly discloses that there is a significant difference of the educational level of the head householders according to poor and non-poor households. Educational level of the majority of poorer head householders is at primary level or below but the majority of non-poor head householders is above primary or secondary level. No schooling percentage is also $9 \%$ of poorer head householders but none of non-poor head householders reported to the category of no schooling. Thus, it is clear that the educational level of non-poor householders in the division is higher than that of poor householders.

As emphasized by the Human Development Report (2000/2001), it is interesting to examine whether the households with limited education tend to be more subject to income fluctuations. For this purpose, educational level of these two groups and their coefficient of the variation of income were compared. The comparison confirmed that there is a clear difference of educational level between these two groups and their coefficient of the variation of income also varies accordingly.

\subsubsection{Income diversification of poor and non-poor households}

Diversification of income can also be used as a good technique to measure the vulnerability of poor and non-poor households. Generally, it is assumed that the households having more diversified income with different sources are less vulnerable compared to those households with limited sources of income. Yet, sometime income diversification is not itself enough to understand the vulnerability because the certainty of income may be more important than the diversification of income. Some time there may be some households with one source of income but less vulnerable due to its certainty. On the other hand, some households may have different sources of income but more vulnerable due to their uncertainty. Therefore, the number of sources of income as main or supplementary and their certainty as fixed or variable sources are very important aspects in understanding the nature of vulnerability.

Thus, the first step of the analysis is to examine whether their main source of income is certain or uncertain. Table 6 indicates the nature of certainty of the main source of income of poor and non-poor households, according to four scales examined in the research process.

\begin{tabular}{|l|c|c|}
\hline \multirow{2}{*}{ Level of certainty of the main source of income } & \multicolumn{2}{|c|}{ Neboda West GN Division } \\
\cline { 2 - 3 } & $\%$ of poor households & $\begin{array}{c}\text { \% of non-poor } \\
\text { households }\end{array}$ \\
\hline Highly certain & - & 14 \\
\hline Certain & 18 & 64 \\
\hline Uncertain & 82 & 22 \\
\hline
\end{tabular}




\begin{tabular}{|l|c|c|}
\hline Highly uncertain & & \\
\hline Percentage total & 100.0 & 100.0 \\
\hline
\end{tabular}

Table 6: Certainty of the main source of income by poor and non-poor households

Source: Field data, 2019

Table 6 illustrates percentage value of the poor and non-poor households reported to each category of certainty levels of their main source of income. Accordingly, it can clearly be demarcated that main source of income of the majority of nonpoor households is certain while that of poor households is uncertain.

In addition to the main source of income, whether these households have any supplementary sources of income is also an important aspect in understanding the nature of vulnerability of these two groups, as it is assumed that when the income is more diversified then such households are less vulnerable. Thus, the Table 7 indicates the number of supplementary sources of income belonging to poor and non-poor households in the selected GN division.

\begin{tabular}{|l|c|c|}
\hline \multirow{2}{*}{ Number of supplementary sources of income } & \multicolumn{2}{|c|}{ Neboda West GN Division } \\
\cline { 2 - 3 } & $\%$ of poor households & $\begin{array}{c}\text { \% of non-poor } \\
\text { households }\end{array}$ \\
\hline One & 45 & 64 \\
\hline Two - Three & 55 & 36 \\
\hline More than Three & - & 100.0 \\
\hline Percentage total & 100.0 & 100. \\
\hline
\end{tabular}

Table 7: Number of supplementary sources of income by poor and non-poor households

Source: Field data, 2019

Table 7 clearly indicates that the income of poor households is more diversified than that of non-poor households, as the supplementary income of poor households is composed of one or more sources. Particularly, compared to non-poor households, percentage value of the poor households with two-three supplementary sources is higher by confirming more diversified income sources within poor category. Thus, we can conclude that the income of the poor with more diversified sources is more stable than that of the non-poor. But before concluding so, it is advisable to examine the extent to which their supplementary sources of income are certain or not because the certainty of sources is more important than the number of sources in understanding vulnerability.

Accordingly, Table 8 indicates the certainty of supplementary sources of income of the poor and non-poor households, based on four certainty levels examined in the research process.

\begin{tabular}{|l|c|c|}
\hline \multirow{2}{*}{ Nature of certainty of supplementary sources of income } & \multicolumn{2}{|c|}{ Neboda West GN Division } \\
\cline { 2 - 3 } & $\begin{array}{c}\text { \% of poor } \\
\text { households } \\
\text { households }\end{array}$ & - \\
\hline Highly certain & - & 64 \\
\hline Certain & - & 36 \\
\hline Uncertain & 18 & - \\
\hline Highly uncertain & 82 & 100.0 \\
\hline Percentage total & 100.0 & \\
\hline
\end{tabular}

Table 8: Certainty of supplementary sources of income by poor and non-poor households

Source: Field data, 2019 
According to the data in Table 8, it is evident that the supplementary sources of income of poor households are not certain at all. When compared to non-poor category, uncertainty of supplementary sources of income is so high within poor category, as the percentage value of highly uncertain category of the poor is 82 percent. Even though the income of poor households is more diversified with many supplementary sources of income, it is evident that poor households are more vulnerable compared to non-poor households, as such sources are highly uncertain.

\subsubsection{Links to family and social networks of poor and non-poor households}

Family-based networks, occupation-based groups of mutual help, rotating savings and credit groups or associations to which a household belongs are considered as household's social capital. Such social capital can also be a source of transfers in cash or some other way in the event of a calamity. Therefore, in understanding the nature of vulnerability of the poor and nonpoor it is important to examine the extent to which such networks have been established in their household setting.

Thus, Table 9 indicates the percentage distribution of poor and non-poor households with such links to different family and social networks.

\begin{tabular}{|l|c|c|}
\hline \multirow{2}{*}{$\begin{array}{l}\text { Nature of the link to family and social } \\
\text { networks }\end{array}$} & \% of poor households & $\begin{array}{c}\text { \% of non-poor } \\
\text { households }\end{array}$ \\
\cline { 2 - 3 } Family based network & 18 & 57 \\
\hline Occupational based network & - & 71 \\
\hline Rotating savings & 64 & 50 \\
\hline Credit groups & 90 & 14 \\
\hline
\end{tabular}

Table 9: Links to family and social networks by poor and non-poor households

Source: Field data, 2019

Family based networks indicate mutual supportive environment from the members of the family and relatives. In this regard, financial or material support given in a calamity was particularly taken into consideration, as such supports directly help to minimize adverse shocks in a vulnerable situation. Occupational based networks are associated with the environment of working place and different supports such as employer support, co-partners' and other employees' support, welfare society or union support given in a calamity belong to this type of linking networks. Rotating savings particularly mean the system of Cheetu, which is very popular among village level but some time that system may function even within office environment. Credit group particularly refers to small level groups and societies functioning at village or office level to support each other financially from a fund developed by the group itself.

According to the Table 9, it is evident that family based supports are at higher level in non-poor households. As mentioned by non-poor householders, particularly their relatives support them materially and financially suppose they face to some kind of adverse shock. Their occupational based support is also at significant level, as 71 per cent of non-poor householders have stated that they have some kind of occupational level support in a vulnerable situation. However, such family based or occupational based supports are at very low level in poor households. Their occupational based support is worse than that of family based supports because none of poor householders mentioned that they have occupational based support in a vulnerable situation.

However, this image is totally different regarding rotating savings and credit group links between these two groups. Particularly Cheetu system and small credit groups of women are very popular among poor households and as a way of smoothening consumption, many poor households have joined to the credit groups and Cheetu system. Not only for consumption smoothening but also in vulnerable situation, these small credit groups have so far mutually supported to each other of poor households. As they mentioned, it has immensely contributed to face to the unexpected adverse shocks. 


\subsubsection{Participation in formal safety nets by poor and non-poor households}

It is assumed that household's vulnerability is reduced if it is entitled to social assistance, unemployment insurance, pensions and other publicly provided transfers. Therefore, it is important to examine the extent to which such formal safety environment could be identified regarding these two groups. The Table 10 indicates the nature of such formal safety nets according to poor and non-poor households.

\begin{tabular}{|l|c|c|}
\hline \multirow{2}{*}{ Nature of formal safety nets } & \multicolumn{2}{|c|}{ Neboda West GN Division } \\
\cline { 2 - 3 } & $\begin{array}{c}\text { \% of poor } \\
\text { households of non-poor } \\
\text { households }\end{array}$ \\
\hline Social assistance & 18 & 14 \\
\hline Insurance & - & 43 \\
\hline Pensions & - & 14 \\
\hline $\begin{array}{l}\text { Other publicly provided transfers (workfare programmes, social } \\
\text { funds etc.) }\end{array}$ & - & - \\
\hline
\end{tabular}

Table 10: Participation in formal safety nets by poor and non-poor households

Source: Field data, 2019

As a whole, data in Table 10 discloses that the participation in formal safety nets is in a very poor level in both groups. In case of social assistance, whether some form of social donation or support are received by poor or non-poor households were examined. As indicated by the Table 10, few families from both groups mentioned that they receive such type of social assistance. In this regard, there was no clear demarcation between poor and non-poor households. Security from insurance as a formal safety net is comparatively high in non-poor households. 43 percent of non-poor households have the insurance suppose they face to adverse shock but poor households are more vulnerable in terms of such formal safety network. As mentioned by them, they are not in a position to go for such insurance due to their poor economic background and income. Even regarding pensions, the situation is same as almost all poor householders are non-pensionable. Majority of non-poor householders are also non-pensionable, as they are also not employed in government and private sector mainly. Other publicly provided transfers such as social fund, workfare programmes etc. cannot be identified regarding both groups.

\subsubsection{Access to credit market by poor and non-poor households}

The extent to which poor and non-poor householders have access to credit market is also a good indicator in understanding whether they are vulnerable or not. Normally, it is accepted that household's vulnerability is reduced if it has access to credit, particularly for consumption smoothening. Therefore, whether these households have access to formal and informal credit market, particularly in a sudden situation, was evaluated and their responses were analysed as indicated in Table 11.

\begin{tabular}{|l|c|c|}
\hline \multirow{2}{*}{ Nature of credit market } & \multicolumn{2}{|c|}{ Neboda West } \\
\cline { 2 - 3 } & \% of poor & \% of Non-poor \\
\hline Formal & - & 57 \\
\hline Informal & 45 & 100 \\
\hline
\end{tabular}

Table 11: Access to Credit Market by Poor and Non-poor Households

Source: Field Data, 2019

Formal credit market refers to legalized financial institutions like banks and other formal financial institutions. Money lenders at high interest rates fall to the category of informal credit market. According to the data in Table 11, it is evident that there is a clear difference between poor and non-poor households regarding the access to formal credit market. Poor householders mentioned that they do not have any access to formal credit market. As pointed out by poor householders, their poor economic background is the main reason for not having such access. As the formal financial institutions normally ask some security or bond when providing loans, they find difficulties to provide such security according to their poor economic 
background. Householders in poor category are mainly doing casual works and due to this reason they do not have fixed income sources to produce such securities. They do not have valuable fixed assets as well to produce as security bonds. Due to this reason, many households in poor group have tended to go behind informal money lenders, demanding high interest rates monthly.

Not only for the formal financial market but also for the access to informal credit market is also limited in poor households compared to non-poor households. As disclosed by the data in Table 11, all households in non-poor category do not have any issue of accessing to informal credit market but the percentage of poor households having such access to informal credit market is only 45 per cent. Householders in non-poor category mentioned that they do not have any problem of getting a loan from informal market, as money lenders know that they pay back on time without problem. But the householders in poor category face difficulties, even getting a loan from informal money lenders, as they have the doubt of their repayment capacity due to their poor economic background. Therefore, poor householders are always vulnerable of adverse shocks, as they are not supported by either formal or informal financial market. They face serious issues of how to smoothen their consumption in such situation.

\section{Conclusions}

As a whole, this study was done to understand the vulnerability of the poor and non-poor households in the selected GN division of Dodangoda Divisional Secretariat. For this purpose, households were selected with the main view of testing whether there is a significant difference between these two groups in terms of the concept of vulnerability. In the research process, the nature of vulnerability of these two groups was quantitatively and qualitatively analysed. Thus, the followings were found as the outcome of the research.

From the first section of quantitative analysis, it was confirmed that the average monthly income significantly varies between poor and non-poor households in the division. The Analysis of Variance further confirmed that this difference is statistically significant. Not only in terms of the average monthly income but also in terms of the variability of income there is a significant difference between these two groups. The coefficient of variation is higher in poor group than the non-poor group by confirming that the variability of monthly income of poor group is higher than that of non-poor group.

The second section of the study focused on qualitative dimensions of vulnerability with a view of understanding whether there is a significant difference of qualitative dimensions of vulnerability between poor and non-poor households. Ownership of the household's physical assets, possibility of liquidising such assets, nature of human capital, income diversification, nature and the certainty of supplementary sources of income, links to family and social networks, participation in formal safety nets and access to credit market were evaluated in this regard.

The analysis clearly discloses that there is a significant difference of the ownership of different physical assets by poor and non-poor households. This difference is so salient in terms of the ownership to paddy and other lands, motor vehicles and jewelleries. As the ownership to different physical assets is not merely enough in understanding the reality of vulnerability well, the extent to which such different assets can immediately be liquidized was evaluated. Particularly, the capability of liquidising jewellery, motor vehicles, foot and motor bicycles, three wheelers and poultry as immediate liquidizing assets was examined. Accordingly, this study strongly confirms that the immediate possibility of liquidising the assets in an adverse situation significantly varies according to poor and non-poor households. These findings emphasize that the poor households are weak not only in terms of the ownership to physical assets but also in terms of liquidizing such assets.

Human capital of the poor and non-poor households was evaluated in terms of the educational level of the head householder as the Human Development Report (2000/2001) has pointed out that the households with limited education tend to be more subject to income fluctuations. In order to examine the validity of this matter, this study examined whether there is a difference of the educational level of poor and non-poor households in the selected village. The focus of this analysis was to examine the difference of education according to poor and non-poor and to examine such difference could be related to the income fluctuation of these two groups. The analysis confirms that there is a clear difference of the educational level between these two groups. Their coefficient of variation of income also varies by confirming the households with limited education tend to be more subject to income fluctuations.

Diversification of the income of poor and non-poor households was also analysed as it is generally assumed that the households having more diversified income with different sources are less vulnerable compared to those households with limited sources of income. This assumption was rejected by the findings. The analysis confirmed that the income of poor households is more diversified than that of non-poor households but their main as well as supplementary sources of income are so uncertain compared to the sources of income of non-poor households. Even though the number of sources of income 
of non-poor households is limited they are fixed and certain making them less vulnerable. Thus, from this study it was confirmed that the certainty of income is more important than the diversification of income, as the poor householders are more vulnerable in different circumstances due to the uncertainty of their income sources. Particularly this study confirmed that poor households have been directed to find different sources due to high uncertainty of the sources.

Different family and social networks to which a household belongs, can also be a source of transfers in cash or some other way in the event of a calamity. Therefore, the extent to which such networks have been established in poor and non-poor household setting was examined. Thus, the study confirmed a significant difference of family and occupational based support and network between poor and non-poor households. Compared to the poor, family and occupational based support was at higher level in non-poor households. Supports given by their relatives, employers, welfare societies and co-workers in a vulnerable situation were salient in this regard. But that supportive environment could not be identified in poor household set up.

However, the findings were totally different between these two groups regarding rotating savings and credit group links. Particularly cheetu system and small credit groups of women are very popular among poor households as a way of smoothening consumption. Such systems have immensely contributed to face to the unexpected adverse shocks of poor households. But such credit group system is not salient in non-poor households as a social safety network.

It was assumed that household's vulnerability is reduced if formal safety environment is established in household set up. Therefore, households' participation in formal safety nets was examined regarding these two groups. Social donation or support given in a vulnerable situation, security from the insurance, publicly provided transfers such as social fund and workfare programmes were the aspects examined in this regard. Thus, the study confirmed that a clear demarcation cannot be identified between poor and non-poor households in terms of social assistance received in a vulnerable situation. But the number of poor families receiving social assistance is comparatively higher than number of non-poor households.

As a formal safety net, non-poor households have the security from insurance in a vulnerable situation but the study confirmed that poor households are more vulnerable in terms of such formal safety network. Poor economic background and the low income of the poor is the reason for their inability to go for such insurance. As poor householders are mainly doing casual works they are not entitled to pension schemes as well. However, a clear difference could not be identified in terms of publicly provided transfers as it could not be identified regarding both groups.

Normally, it is accepted that a household's vulnerability is reduced if it has access to credit particularly for consumption smoothening. Therefore, the extent to which poor and non-poor householders have access to formal and informal credit market was examined in this regard. Thus, the study confirmed that there is a clear difference between poor and non-poor households regarding the access, particularly to formal credit market. Poor economic background and the lack of physical assets have limited the access of poor households to the formal credit market. Not only the access to formal credit market but also the access to informal credit market is limited in poor householders. Due to this reason poor households are more vulnerable in adverse situations compared to non-poor households.

\section{References}

[1] Attanayake, N. (2003). Poverty and health: Vulnerability of the plantation community, Poverty Issues in Sri Lanka. Orugodawatte: Gunarathna Offset Limited.

[2] CARE International (2000). Household livelihood security assessment in LTTE controlled areas in Wanni. WFP and CARE International: Colombo.

[3] Chambers, R. (1989). Vulnerability, coping and policy, vulnerability: How the poor cope. IDS Bulletin, 21 (2), 1-7.

[4] Dercon, S. (2002). Income risk, coping strategies and safety nets. World Bank Research Observer, Oxford University Press, 17(2), 141166.

[5] Elbers, C. \& Gunning, J.W. (2003). Vulnerability in a stochastic dynamic model. Tinbergen Institute Discussion Papers, 03-070/2, Tinbergen Institute.

[6] Fauci, A.J., Bonciani, M. \& Guerra, R. (2012). Quality of life, vulnerability and resilience: A qualitative study of the tsunami impact on the affected population of Sri Lanka. Ann Ist Super Sanita, 48(2), 177-188.

[7] Gaiha, R., Imai, K. \& Kang, W. (2007). Vulnerability and poverty dynamics in vietnam. The Second School of Economics Discussion Paper Series, Economics, The University of Manchester.

[8] Jonathan, M. (1995). Income smoothening and consumption smoothening. Journal of Economic Perspectives, American Economic Association, 9(3), 103-14.

[9] Lant, P., Asep, S. \& Sudamo, S. (2000) ‘Quantifying vulnerability to poverty - A proposed measure, applied to Indonesia. Policy Research Working Paper Series, 2437, The World Bank. 
[10] Ligon, E. \& Schechter L. (2003). Measuring Vulnerability. Economic Journal, 113 (486), C95-C102Katsushi, S., Wang, X. \& Kang, W. (2009). Poverty and vulnerability in rural China: Effects of taxation. The Second School of Economics Discussion Paper Series, Economics, The University of Manchester.

[11] Raghbendra, J. (2009). Poverty, under nutrition and vulnerability in rural India: Public works verses food subsidy. ASARC Working Papers, 2008-08, Australian National University.

[12] Silva, T.K. (2003). Perceptions of vulnerability and coping in conflict-affected populations: Interplay among poverty, ethnicity and conflict in dry zone Sri Lanka. Poverty Issues in Sri Lanka, Orugodawatte, Gunarathna Offset Limited.

[13] Suryahadi, A. \& Sumarto, S. (2003). Poverty and vulnerability in Indonesia'. Asian Economic Journal, 17(1), 45-64

[14] Unhabitat (2012). Negombo Sri Lanka: Climate change vulnerability assessment. Negombo: Municipal Council.

[15] World Bank. (2000/2001). World Development Report. World Bank: Washington DC.

[16] Yamane, A. (2003). Rethinking vulnerability to climate change in Sri Lanka'. Ninth International Conference on Sri Lanka Studies, Matara, Sri Lanka. 